\title{
A Low Cost Weather Balloon Borne Solar Cell Calibration Payload
}

\author{
David B. Snyder and David S. Wolford \\ NASA Glenn Research Center, Cleveland, OH, 44135, USA
}

\begin{abstract}
Calibration of standard sets of solar cell sub-cells is an important step to laboratory verification of on-orbit performance of new solar cell technologies. This paper, looks at the potential capabilities of a lightweight weather balloon payload for solar cell calibration. A $1500 \mathrm{gr}$ latex weather balloon can lift a $2.7 \mathrm{~kg}$ payload to over $100,000 \mathrm{ft}$ altitude, above $99 \%$ of the atmosphere. Data taken between atmospheric pressures of about 30 to 15 mbar may be extrapolated via the Langley Plot method to 0 mbar, i.e. AM0. This extrapolation, in principle, can have better than $0.1 \%$ error. The launch costs of such a payload are significantly less the the much larger, higher altitude balloons, or the manned flight facility. The low cost enables a risk tolerant approach to payload development. Demonstration of $1 \%$ standard deviation flight-to-flight variation is the goal of this project. This paper describes the initial concept of solar cell calibration payload, and reports initial test flight results.

Index Terms - aerospace testing, photovoltaic cells, solar power generation, solar simulator, solar cell calibration, space power, space technology.
\end{abstract}

\section{INTRODUCTION}

Calibration of standard sets of solar cell sub-cells is an important step to laboratory verification of on-orbit performance of new solar cell technologies [1]. As long as the photon density in the appropriate wavelength bands reaching each sub-cell is correct, laboratory measurements are very accurate at reproducing on-orbit performance. Present facilities capable of supporting calibration measurements of the short circuit current, Isc, near or at Air Mass Zero, AM0, include the CNES high altitude facility, CASABOLA [2], and the NASA GRC Lear Jet [3]. A new high altitude balloon facility, Near-Space Characterization of Advanced Photovoltaics, NSCAP, is being developed jointly by AFRL, NRL and NASA to replace the former JPL balloon facility [4].

Woodyard [5] investigated the possibility of building a self contained lightweight payload, Sun Tracker, for solar cell calibration. Fourteen flights were conducted between 1999 and 2005. These flights demonstrated a sun acquisition mechanism, and that it is possible to make Isc measurements in a payload that can fly as "exempt" under FAR 101[6] section 101.1(4), which provides Federal regulation of high altitude balloon flights. Funding limitations ended NASA GRC's support for this program.

This experience has led to a modified approach to solar cell measurements discussed here. These include: (1) using flight data above most of the ozone layer, where the ozone ratio in the atmosphere becomes nearly uniform, to extrapolate to AM0 via a Langley Plot extrapolation, (2) adjust the cell holder stage angle to match the Sun altitude angle, (3) use a sun sensor to identify when the naturally rotating payload is sufficiently aligned with the sun to trigger a set of solar cell short circuit current measurements, (4) use a shade system to limit reflections from the balloon and lower atmosphere, and (5) heat the cell holder stage to control the cell temperature.

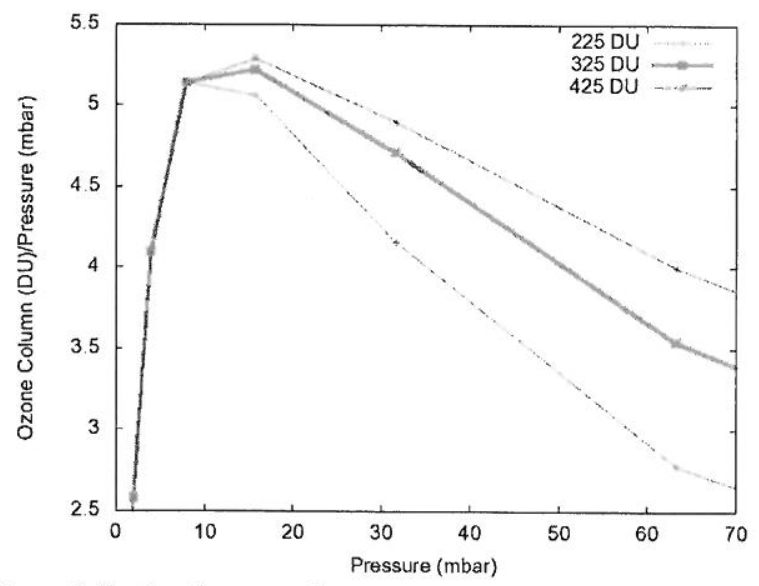

Figure 1. Ratio of ozone column to pressure.

Figure 1 illustrates the ratio of Ozone column density in Dobson Units (DU) to pressure, for atmospheric pressure from 2 to 70 millibar, for three different total ozone column numbers. The Ozone column density is the amount of ozone in the atmosphere above a specific altitude or pressure. The Total Ozone Number is the amount of ozone in the atmosphere down to ground level. Distributions for three Total Ozone numbers are plotted in the figure: 225, 325, and 425 Dobson Units. These profiles are from TOMS Version 7 Standard Ozone Profiles [7]. For the range of $4 \mathrm{mb}$ to $35 \mathrm{mb}$ these ratios range from 4 to 5 , relatively uniform as expected if the ozone producing UV radiation were not significantly attenuated passing through these atmospheric layers. The portion above $4 \mathrm{mb}$ is small. Following the analysis of reference [8], the pressure based extrapolation introduces an error of $<0.1 \%$ to the most sensitive InGaP top cell of a triple cell set.

The goal of this effort is to measure calibration Isc with an accuracy of $\pm 1 \%$ standard deviation. This is less than the $0.5 \%$ expected for space power system analysis, but it would 
provide the capability to distinguish between a $30 \%$ and a $30.3 \%$ efficient cell. This capability would be sufficient to support the research level identification of the expected maximum power improvements as new solar cell technologies develop.

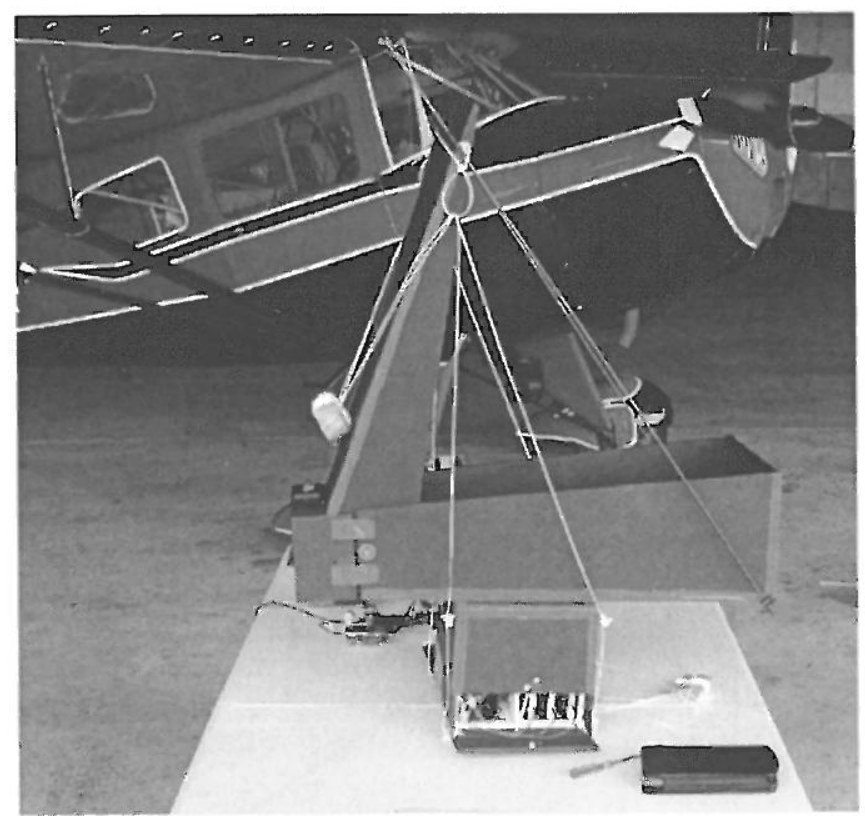

Figure 2. Solar Cell Calibration payload boxes.

The goals of the initial flights are to: 1) show the solar cell can survive the flight and be recovered. 2) Establish that enough data can be taken during a flight. That is ten or more points per cell within $5^{\circ}$ of the sun, over a factor of $1 / 2$ of pressure change, above most of the ozone layer, i.e. $30 \mathrm{mbar}$. 3) That the temperature of the cells can be controlled to $\pm 2 \mathrm{C}$. 4) Flight-to-flight reproducibility of the extrapolated AM0 Isc of $1 \%$. 5) Data acquisition for up to four $2 \times 2 \mathrm{~cm}$ solar cells per flight. The first two of these goals are demonstrated here.

\section{EQUIPMENT}

\section{A. Balloon}

Lightweight payloads can be carried aloft by latex balloons that extend as they rise until they burst. A $1200 \mathrm{gr}$ balloon can carry a $1 \mathrm{~kg}$ payload to $109 \mathrm{kft}$ [9]. A $1500 \mathrm{gr}$ balloon can carry a $1 \mathrm{~kg}$ payload to $112 \mathrm{ft}$. Based on experience, a $2.7 \mathrm{~kg}$ payload can be carried to near $95 \mathrm{kft}$ by a $1200 \mathrm{gr}$ balloon, or $100 \mathrm{kft}$ by a $1500 \mathrm{gr}$ balloon. In either case the balloon can be inflated using one K-Bottle of Helium. Rise rates are planned near $1000 \mathrm{ft} / \mathrm{min}$. The mission duration can be reduced with more inflation gas which both increases the rise rate and reduces the burst altitude. A $7 \mathrm{ft}$ parachute is used. Descent times range from 35 to 40 minutes.

\section{B. Payload boxes}

The solar cell calibration payload consists of two boxes shown in figure 2. The prototypes are constructed from black $3 / 16$ " foam core to minimize internal reflections. The joints are glued using a silicon adhesive. The cell holder box consists of two pieces, a ground shade designed to block ground and cloud reflections up to $10^{\circ}$ above the top of the holder. The top balloon shade is also designed with an acceptance angle width of $\pm 5^{\circ}$. Its angle is adjustable and is set to $10^{\circ}$ below the edge of the high altitude balloon, about 5 times the launch diameter, based on the distance below the balloon. The two pieces are connected with small bolts at a pivot point, and carbon fiber rod holds the aperture end separated. The second box, also black foam core, holds most of the electronics, batteries, data acquisition boards, and data loggers. The entire payload, with cell and electronics weighs near $1.5 \mathrm{~kg}$.

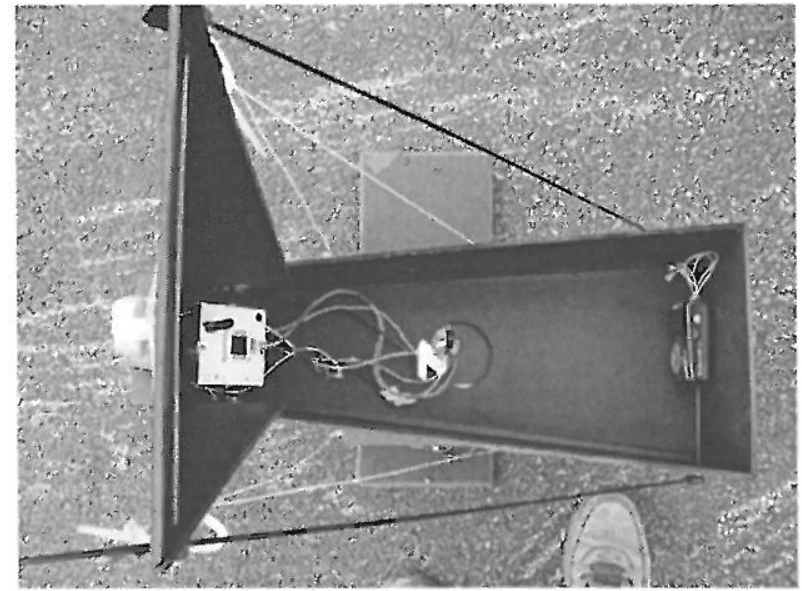

Figure 3. Cell Holder and Camera installed in payload.

The payload has no telemetry. All data is logged and the payload must be recovered to access the data. Presently recovery depends on piggy backing with an amateur or educational payload to transmit Ham Radio APRS, Automatic Packet Reporting System, position and altitude data. A FindMe-Spot ${ }^{\mathrm{TM}}$ is included as a backup location transmitter. It transmits latitude and longitude information at $10 \mathrm{~min}$ intervals, but does not include altitude data, or function at high altitudes.

A camera, Canon A480, views the cell holder during the flight to verify operation of the cell holder plate to track the sun elevation. Figure 3 shows the cell holder on the left side, and the camera on the right side. It is programmed to take pictures at 20 second intervals.

A model rocket beeper is included with the payload as a warning and location aid for when the payload returns to the ground. This helps when the payload lands in tree or in a corn/soy field. 


\section{Cell Holder Stage}

The cell holder stage is designed to hold four $2 \times 2 \mathrm{~cm}$ cells mounted on NSCAP cell carriers [10]. This provides the capability of measuring a full set of triple (or quadruple) subcells during one flight. It also keeps the holder lightweight. The stage is presently $8 \times 8 \mathrm{~cm}$, to be upgraded to $10 \times 12 \mathrm{~cm}$ which would accommodate two $4 \times 8 \mathrm{~cm}$ cells. It is formed from 1/16" thick $2024 \mathrm{Al}$. On the back it includes an RTD temperature sensor and four resistive heaters, $9 \Omega$ total. This supports temperature control of the cells. The NSCAP cell carriers also include temperature sensors, AD590, to document the actual cell temperature during measurements. The stage temperature is logged throughout the flight. Cell temperatures are logged during Isc measurements.

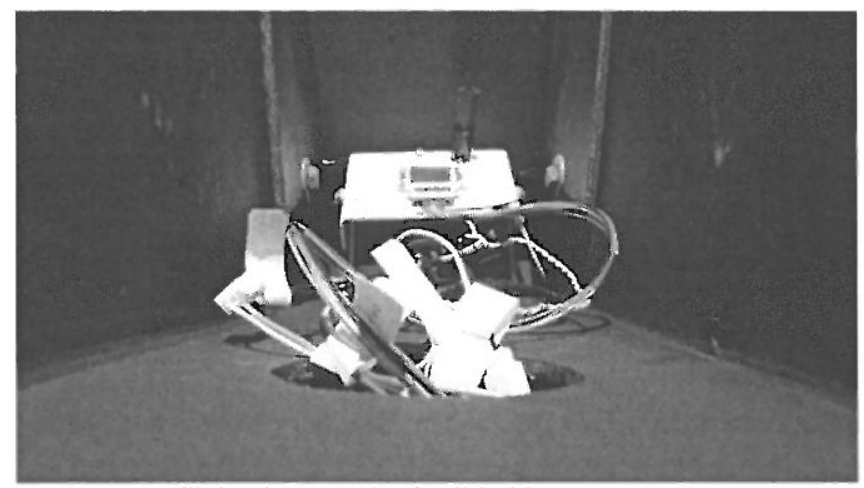

Figure 4:. In-flight photograph of cell holder stage.

$\mathrm{A} \pm 5^{\circ}$ Sun Sensor is included on the stage to trigger cell measurements when cells are directed toward the sun, giving $>0.996$ full sunlight. It consists of a Dexter Research 2M thermopile with a $5.2 \times 0.8 \mathrm{~cm}$ black paper tube to limit the acceptance angle to about $9^{\circ}$. The measured acceptance is somewhat less due to the smaller $2 \mathrm{~mm}$ active area. Figure 5 shows the sun sensor response as the sun passes over it. The width at the $25 \mathrm{mV}$ level is $8.5^{\circ}$. A couple bumps during the test may reduce that by $0.8^{\circ}$ giving a width of $7.7^{\circ}$ or about $\pm 4^{\circ}$. If enough data can be acquired during a flight, a second $2.5^{\circ}$ sun sensor may be added to identify $>.999$ points. The payload will experience pendulum swinging and rotation during the flight. However, if the stage is adjusted for sun angle enough random samplings should occur to make a meaningful set of measurements. If the swinging is less than $5^{\circ}$, using the $5^{\circ}$ senor $1 / 36$ of the data samples may be on-sun, nearly $3 \%$ of the points. For 10 good points over a pressure reduction of $1 / 2,>360$ samples are needed over a $15 \mathrm{kft}$ altitude change, which takes $15 \mathrm{~min}$ at a $1000 \mathrm{ft} / \mathrm{min}$ rise rate. The sampling rate should be at least $2.5 \mathrm{~s} /$ sample. A sampling rate of $1 \mathrm{~s} / \mathrm{sample}$ is used. Using 10 points for a curve fit suggests, via the $t$ test distribution, a $95 \%$ confidence range of 2.23 standard deviations.

The angle of the cell holder is adjusted with a Parallax Standard Servo to match the solar altitude angle to within $1^{\circ}$ throughout the flight, calculated using GPS location and time data, with the Solar Declination and Right Ascension for the time of the flight. The servo gear box was degreased, then sprayed with Fluoroglide F8 ${ }^{\mathrm{TM}}$ as a low temperature lubricant. Linkages were also lubricated similarly.

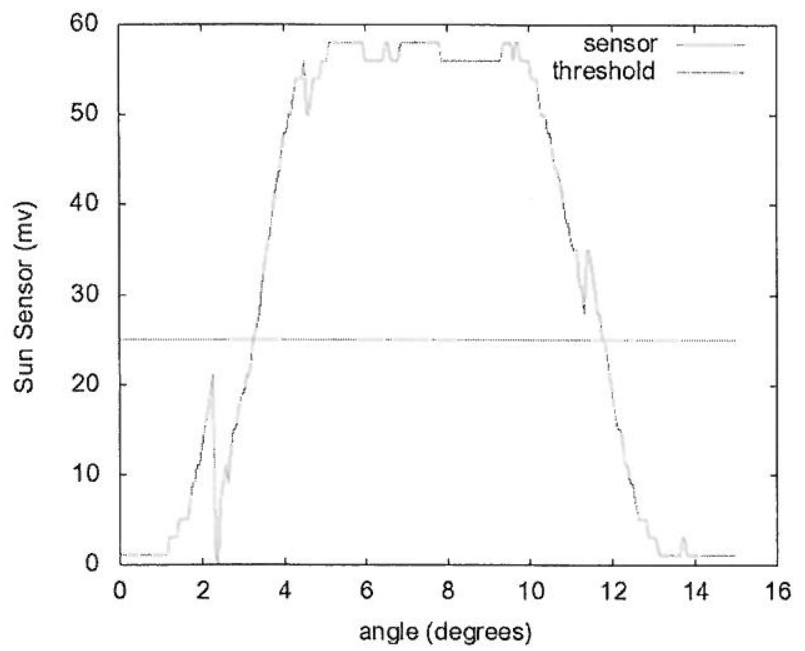

Figure 5. Sun sensor response on ground.

\section{Electronics}

The initial electronics package includes two battery packs of four Lithium $123 \mathrm{~A}$ to provide $12 \mathrm{~V}$ and $1.5 \mathrm{Ah}$. One powers the flight computer boards, the second is dedicated to heating the cell holder stage.

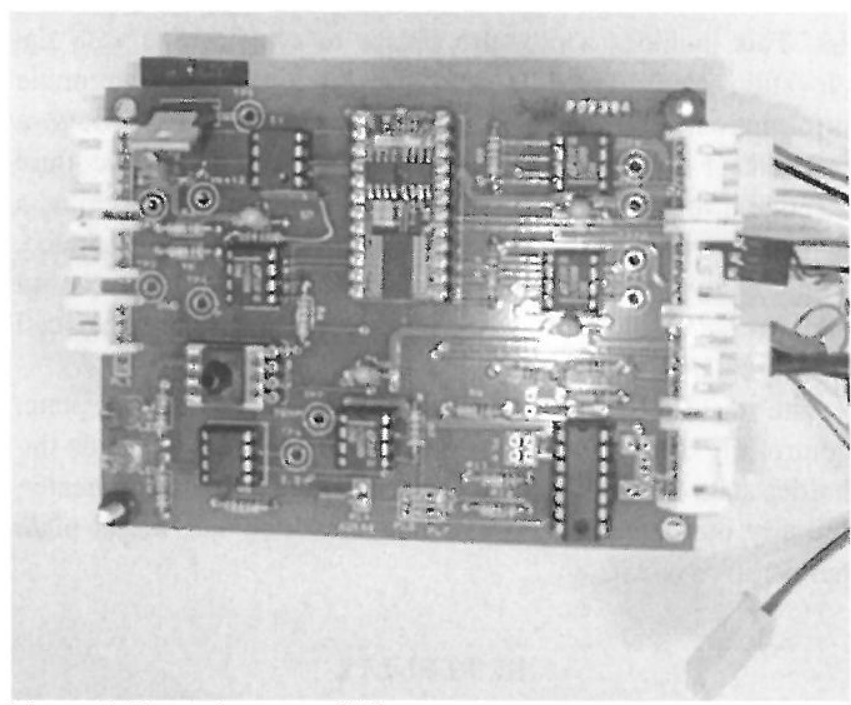

Figure 6. General purpose flight computer.

The general purpose flight computer boards are a $100 \times 76 \mathrm{~mm}$ PCB, designed for use with a Parallax Basic Stamp $2^{\mathrm{TM}}$. The board contains a $5 \mathrm{~V}$ regulator, LM340T5, providing power to the Basic Stamp, and other IC's as well as a reference voltage for the ADC IC's. An 25AA1025 provides 
$128 \mathrm{~K}$ bytes of data storage and four LTC1298 provide a total of eight channels of 12-Bit Analog to Digital Conversion, ADC. In addition to the 3-pin power connector, the board includes five 5 pin connectors and a second 3-pin connector. One 5-pin connector is used as an RS232 interface for programing the micro-controller and downloading data. Each of the remaining 5-pin connectors include a $+5 \mathrm{~V}$ power and common pin. Two connectors include 2 pins connecting to each channel of an LTC1298 for analog data acquisition. The inputs to one LTC1298 is amplified and one unamplified. The remaining two 5-pin connectors include direct connections to the Basic Stamp pins for digital IO and control. One uses three pins, the other two pins.

On-board sensors are read with the remaining two LTC1298. A resistive voltage divider provides a measurement of the battery voltage. A Honeywell 015PAAB5 SSC series pressure sensor, and AD590 temperature sensor to monitor temperature on the board. A quad op amp, LM2902, is used to provide 10x amplification of the AD590 signal, as well as the two signals to the amplified LTC1298 ADC.

The first board is used to control the elevation angle of the holder plate. It reads location and time from a GPS, calculates the sun altitude and sets the servo accordingly with a resolution of $2^{\circ}$. It also logs the pressure sensor, board temperature, and holder stage temperature latitude, longitude (1 deg) a coarse $(0.1 \mathrm{hr}$ ) time of day, as well as the calculated sun angle, logging at $30 \mathrm{~s}$ intervals. The sun angle is also used to calculate air mass.

The second board reads and logs the solar cell data. It reads the 5 deg sun sensor, and if pointed at the sun, it logs a data set. This includes a pressure sensor to synchronize with the elevation controller data, and provide time and sun angle information. It also reads the short circuit current through a reference $1 \Omega$ resistor and the cell holder, AD590 temperature through a reference $1 \mathrm{k} \Omega$ resistor. As the payload develops, a general purpose computer for each cell will be included, triggered by one card's reading of the sun sensors. This would add an additional three cards to support four solar cell measurements.

The third board controls the temperature of the plate, controlling a relay for the battery heater power. It reads the holder stage temperature, and if too cool, turns on the heater. Initially the heated power is about 10 watts. The target plate temperature is $25 \mathrm{C}$.

\section{RESULTS}

A first version of the payload was flown, demonstrating survivability of the box and protection of the cell, including recovery from a tree. These flights also indicated that the cables should be covered to reduce reflected light. Unheated, the plate reaches $-40 \mathrm{C}$ during the ascent.

The next successful flight demonstrated data acquisition on a Silicon solar cell. The primary question was whether enough data can be taken for a reasonable extrapolation of a Langley plot to zero pressure. 18 points were obtained above 30 mbar. However, the data is noisier than expected and is not suitable for a Langley plot extrapolating. Data was acquired when the sun sensor read above $25 \mathrm{mV}$. Isc and the sun sensor were read together, before storage, to make the process faster. Figure 7 shows the flight data for points where the sun sensor read above $60 \mathrm{mV}$. The maximum reading sun sensor reading was $91 \mathrm{mV}$. This procedure removed the most extraneous points, as well as some of reasonable ones, however 10 points remained.

The average of the 10 readings above $30 \mathrm{mb}(0.035 \mathrm{Air}$ mass) was $164.0 \mathrm{~mA}$ with a standard deviation of $1.3 \mathrm{~mA}$. While the standard deviation is less than $1 \%$, the measurement appears to be declining as pressure decreases. This is disturbing. The noise may be related to the rapidly changing signal and the slow processor measurements. This will be investigated further.

Figure 7 also includes a plot of data corrected to $25 \mathrm{C}$ using a temperature coefficient of $0.05 \% / \mathrm{C}$. This is only to provide some perspective.

Resolution of the current measurement is $0.2 \mathrm{~mA}$. A one percent measurement would be $\pm 1.6 \mathrm{~mA}$ in this case. For a GaAs middle subcell, the ozone related current change is $0.4 \%$ to $0.2 \%$ for 30 to $15 \mathrm{mbar}$, and similar for the Rayleigh and molecular absorption [8]. The $\mathrm{Si}$ cell changes might be smaller than this estimate. While a $1 \%$ measurement can be made directly at these altitudes, a more precise measurement, $0.5 \%$ or better, would leave a portion of the error budget for flight-to-flight variations.

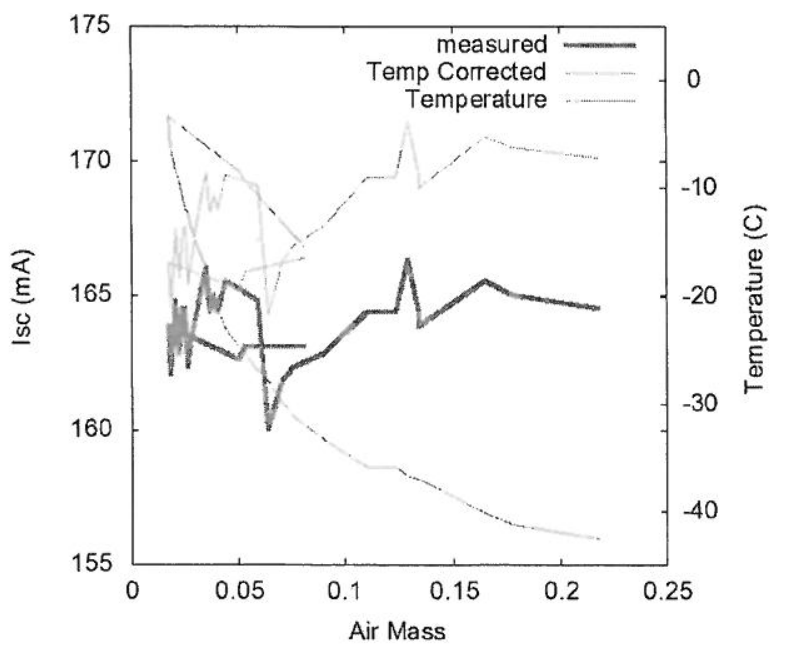

Figure 7. Flight Data above tropopause.

Issues that may need to be addressed to improve the measurements include: whether the balloon may have been visible to the cell, reflections from the wiring, noise in the A/D conversion, transient changes in the current as the cell came on-sun. The temperature control will also revisited for the 
next flight.

Three flights of triple junction sub-cells are planned to examine the flight-to-flight reproducibility of this data. Those flights will demonstrate how well the system is understood.

\section{CONCLUSION}

A lightweight, weather balloon payload to measure short circuit current for calibrating solar cells appears feasible. Langley Plot extrapolations of data acquired in altitude ranged above $75 \mathrm{kft}$ to at least $90 \mathrm{kft}$, are expected to provide AM0 Isc measurements good to a $1 \%$ standard deviation. Flight tests of such a payload are in progress.

The boxes used for payload construction provide protection for the cell, even during recovery from trees. In a test flight, we have acquired 10 data points, the desired number. The standard deviation of data for one flight is $<1 \%$. However, this is not sufficient for a Langley plot extrapolation. Also, that lower altitude data appears higher is disturbing.

The next steps include attempting to reduce the measurement noise in the $\mathrm{I}_{s c}$ data, and implementing temperature control of the plate. The final step will be to verify that the Langley plot method appears to work with this apparatus, and is reproducible over three flights.

If validated, this method will provide low cost access to AM0 solar cell measurements, suitable for verifying the performance of new solar cell technologies as they are developed.

\section{ACKNOWLEDGEMENT}

We would like to gratefully acknowledge the support of Emcore for this work, by providing sets of sub-cells for the flight-to-flight reproducibility portion of this work. We would also like to thank the team of enthusiasts who have supported the launch and recovery efforts: Joseph DeMeyer, Thomas Morton, Jeremiah McNatt, Maciej Zborowski, Steven Krone, Bruce Bream, Corey Best, and Manfred Glatz. Finally, we would like to thank Larry Fruth and Martin Still for the use of facilities at Wyandot County Airport, Upper Sandusky, $\mathrm{OH}$ for the balloon launches.

\section{REFERENCES}

[1] P. Jenkins, et al, "Results from an International Measurement round Robin of III-V Triple-Junction Solar Cells Under Air Mass Zero", 2006 IEEE $4^{\text {th }}$ World Conference on Photovoltaic Energy conversion, 1-4244-0016-3/06, 2006, pp 1968-1970.

[2] V. Pichetto, et al, "CASOLBA Calibration of Solar Cells Measurement an Calibration Procedures," Proc. $29^{\text {th }}$ IEEE Photovoltaics Specialists Conference., New Orleans, 2002. p. 1010.

[3] D. Scheiman, et al., "A Summary of The 2000-2001 NASA Glenn Lear Jet AM0 Solar Cell Calibration Program," 17th Space Photovoltaic Research and Technology Conference, NASA/CP-2002-211831, 2002, pp.195-201.

[4] D. Wilt et al, "High Altitude Solar Cell Calibration Update", 21st Space Photovoltaic Research and Technology Conference, Cleveland, OH, Oct 6-8, 2009, p174-179 http://www.grc.nasa.gov/WWW/SPRAT/SPRAT\%20XXI \%20Final.pdf, Last Accessed 29/01/2012.

[5] James R. Woodyard et al, "High-Altitude Air Mass Zero Calibration Of Solar Cells", 18th Space Photovoltaic Research and Technology Conference, NASA/CP-2005-213431, 2005, pp 148-165.

[6] Federal Aviation Regulations, "PART 101-MOORED BALLOONS, KITES, AMATEUR ROCKETS AND UNMANNED FREE BALLOONS", http://ecfr.gpoaccess.gov'cgi/t/text'text-idx? $\mathrm{c}=$ ecfr\&rgn $=$ div $5 \& v i e w=$ text\&node $=14: 2 \cdot 0 \cdot 1 \cdot 3.15$ \&idno $=14$, Last Access Date 30/01/2012.

[7] Richard D. McPeters, et al. Earth Probe Total Ozone Mapping Spectrometer (TOMS) Data Products User's Guide, NASA TM 1998-206895.

[8] D. Snyder, "Solar Cell Short Circuit Current Errors And Uncertainties During High Altitude Calibrations," $38^{\text {th }}$ IEEE Photovoltaic Specialist Conference, Austin, TX, June 3-8, 2012.

[9] Balloon Characteristics, http://kaymontballoons.com/Weather_Forecasting.html, Last Accessed 30/01/2012

[10] NSCAP 2x2 Cell Holder Diagram Reference Only, http://www.grc.nasa.gov/WWW/SPRAT/ $2 \times 2$ cell $\% 20$ holder \%20NSCAP710.pdf, Last Accessed 30/02/2012. 